\title{
Ionosonde Studies of Some Chemical Releases in the Ionosphere
}

\author{
J. W. Wright
}

\begin{abstract}
Contribution from the Central Radio Propagation Laboratory, National Bureau of Standards, Boulder, Colo.
\end{abstract}
(Received August 13, 1963)

\begin{abstract}
A description is presented of ionosonde observations obtained during the release of chemicals and high explosive detonations in the $E$ and $F$ regions of the ionosphere during Project Firefly 1962. The experiments included several designed to reduce locally the ambient electron density. The effects are discussed in comparison with the calculated ambient electron distributions.
\end{abstract}

\section{Introduction}

Virtually all of the radio techniques exercised over many years for ionospheric explorations are sensitive to only a "trace-element" in the upper atmosphere, the electrons. Despite the significance attached to electrons because of their importance for radio communication, their concentration is to a great extent the incidental by-product of a complex of photochemical and chemical reactions, and the complicated variability of the electron concentration, as observed by radio means, is largely a result of delicate shifts in the equilibria of a variety of reactions involving neutral and ionic species. Thus, relatively small changes in the temperature of the atmospheric constituents, or in the atomic and molecular concentrations, or by the introduction of new molecular species, can have quite disproportionate effects on the electron concentration. Conversely, the great sensitivity of radio techniques to the electron distribution provides an excellent tool by which many aspects of such changes may be detected and studied.

A series of chemical releases from rockets in the high atmosphere, called Project Firefly III, was conducted by the U.S. Air Force Cambridge Research Laboratories at their Eglin (Florida) Rocket Range during October, November, and December 1962. Ionosonde observations were conducted by NBS with the support of AFCRL. Out of a total of 27 successful launchings, the effects of 5 launchings involving a total of 12 chemical releases, will be discussed here. The present results, so soon after the experiments themselves, represent mainly a discussion of the phenomena as observed by an ionosonde; more detailed studies of each experiment are under way, and will be reported at a later date.
An important adjunct to these experiments, is the determination of the ambient electron distribution, $N(h)$, into which the chemicals are released. In a recent contribution, Paul and Wright [1963] have described some results of $N(h)$ calculations by the method of Paul [1960 a and $1960 \mathrm{~b}$ ], using ionograms obtained at Eglin during the Firefly series. It is useful to note that considerable effort was expended to improve the ionosonde technique for these experiments. Specifically, the Model C-4 ionosonde was modified to encompass the 0.25 to $20 \mathrm{Mc} / \mathrm{s}$. observing range (permitting observations of electron densities down to $8 \times 10^{2} / \mathrm{cm}^{3}$ ); a high gain $l o g-$ periodic and switched dipole antenna system was designed [Violette, 1963] and installed to provide useful observations throughout this range. It may be safely said that without these modifications, reliable $N(h)$ profiles could not have been calculated. In a few of the cases to follow, an elementary "monotonic" calculation is compared with the more accurately calculated profile, for further illustration of the errors possible with unimproved ionograms and calculation methods.

\section{Experiments}

The releases discussed here fall into two categories: (a) those in which substances with high electron affinity $\left(\mathrm{SF}_{6}\right)$ or those which might accelerate the natural electron loss processes $\left(\mathrm{CO}_{2}\right)$ were released in the $E$ and $F$ regions, and (b) those where detonation of a pure explosive (HEX) or cesium-salted high explosive (CsHEX) occured in the $F$ region. Various data concerning the six launchings are given in table 1 . 


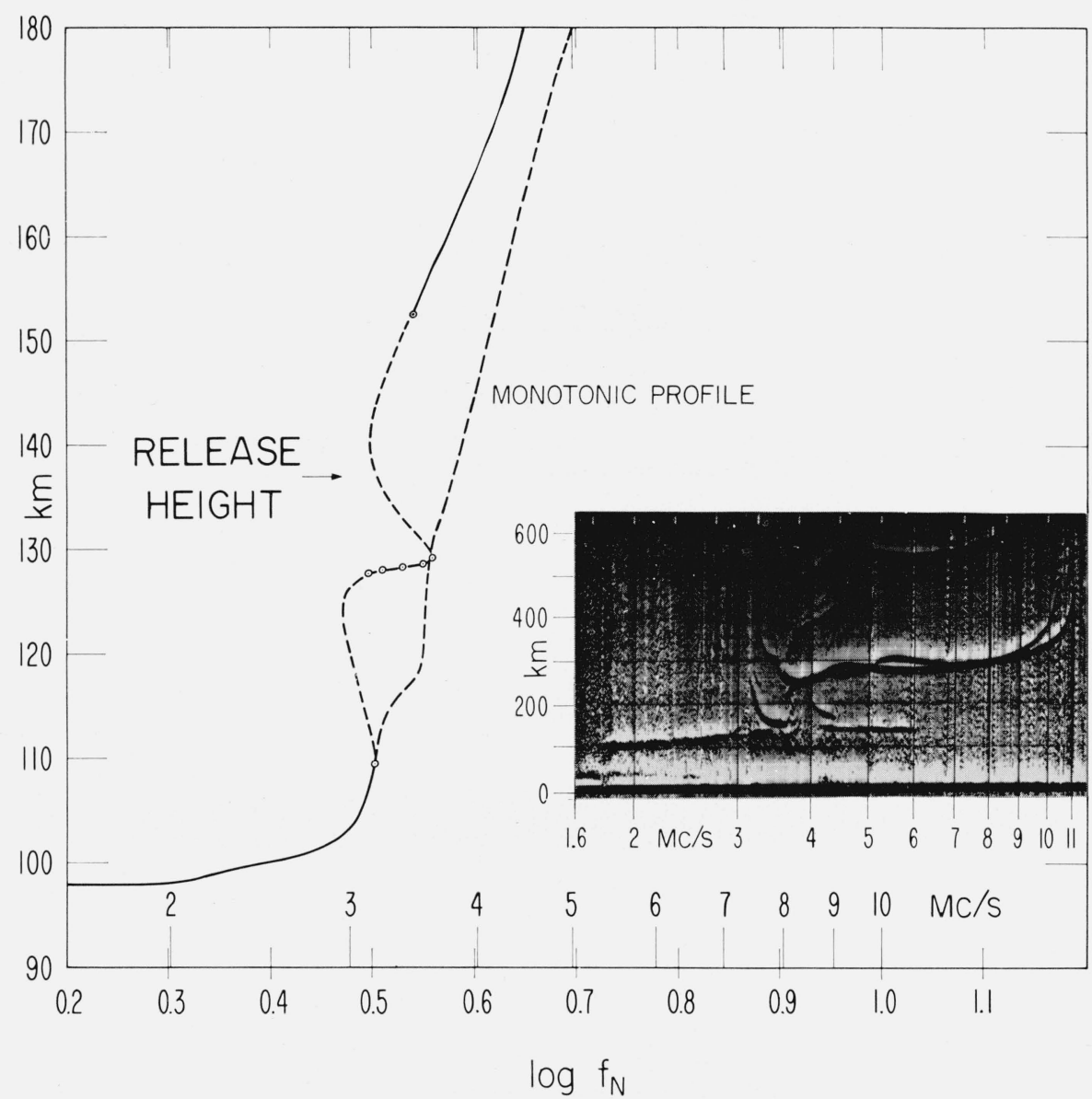

Figure 1. Electron distribution just before Firefly Ethel, 1311 CST 23 October 1962.

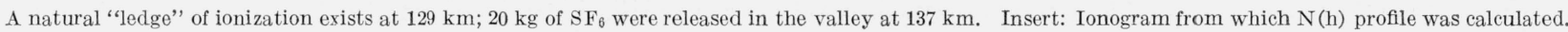

TABLE 1 .

\begin{tabular}{|c|c|c|c|c|c|}
\hline $\begin{array}{l}\text { Name } \\
\text { Date } \\
\text { Launch, } \mathrm{CST}\end{array}$ & $\begin{array}{l}\text { ETHEL } \\
23 \text { Oct. } \\
1310\end{array}$ & $\begin{array}{l}\text { FANNY } \\
10 \text { Nov. } \\
1903\end{array}$ & $\begin{array}{c}\text { GILDA } \\
13 \text { Nov. } \\
1730\end{array}$ & $\begin{array}{c}\text { KAREN } \\
15 \text { Nov. } \\
1926\end{array}$ & $\begin{array}{c}\text { MARTHA } \\
15 \text { Dec. } \\
1130\end{array}$ \\
\hline $\begin{array}{l}\text { Release } 1 \\
\text { Kg. } \\
\text { Alt. Km. } \\
\text { Objective }\end{array}$ & $\begin{array}{c}\mathrm{SF}_{6} \\
20 \\
137 \\
\mathrm{~N}_{\text {e }} \\
\text { Removal }\end{array}$ & $\begin{array}{c}\text { HEX } \\
5 \\
140 \\
N_{e} \\
\text { Perturb. }\end{array}$ & $\begin{array}{c}\text { HEX } \\
5 \\
137.7 \\
\mathrm{~N}_{\mathrm{e}} \\
\text { Perturb. }\end{array}$ & $\begin{array}{c}\mathrm{CO}_{2} \\
5 \\
234 \\
\mathrm{~N}_{\mathrm{e}} \\
\text { Removal }\end{array}$ & $\begin{array}{c}\mathrm{SF}_{6} \\
22.7 \\
222 \\
\mathrm{~N}_{\mathrm{e}} \\
\text { Removal }\end{array}$ \\
\hline $\begin{array}{l}\text { Release } 2 \\
\text { Kg. } \\
\text { Alt. Km. } \\
\text { Objective }\end{array}$ & & $\begin{array}{c}\text { CsHEX } \\
5 \\
157 \\
\text { Ne Perturb. }\end{array}$ & $\begin{array}{c}\text { CsHEX } \\
5 \\
155 \\
\mathrm{~N}_{\mathrm{e}} \text { Perturb. }\end{array}$ & $\begin{array}{c}\mathrm{SF}_{6} \\
20 \\
225 \\
\mathrm{~N}_{\mathrm{e}} \\
\text { Removal }\end{array}$ & \\
\hline $\begin{array}{l}\text { Release } 3 \\
\text { Kg. } \\
\text { Alt. Km. } \\
\text { Objective }\end{array}$ & & $\begin{array}{c}\text { HEX } \\
5 \\
230 \\
N_{\text {e Perturb. }}\end{array}$ & $\begin{array}{c}\text { HEX } \\
5 \\
250 \\
\mathrm{~N}_{\mathrm{e}} \text { Perturb. }\end{array}$ & & \\
\hline $\begin{array}{l}\text { Release } 4 \\
\text { Kg. } \\
\text { Alt. Km. } \\
\text { Objective }\end{array}$ & & $\begin{array}{c}\text { CsHEX } \\
5 \\
260 \\
\mathrm{~N}_{\mathrm{e}} \text { Perturb. }\end{array}$ & $\begin{array}{c}\text { CsHEX } \\
5 \\
237 \\
\mathrm{~N}_{\mathrm{e}} \text { Perturb. }\end{array}$ & & \\
\hline
\end{tabular}

\section{Effects of the Individual Releases}

\subsection{Firefly Ethel}

$20 \mathrm{~kg}$ of $\mathrm{SF}_{6}$ at $137 \mathrm{~km}$ in the daytime $E$-region, 1310 CST, 23 October 1962. The reaction $\mathrm{SF}_{6}+e^{-} \rightarrow$ $\mathrm{SF}_{6-}$ proceeds with a rate $10^{-9} \mathrm{~cm}^{3} / \mathrm{sec}$ for electron energies between $0.1-0.2 \mathrm{ev}\left(750\right.$ to $1500^{\circ} \mathrm{k}$ ) [Golomb, 1962]. It was intended, by this experiment, to examine the properties of a region of reduced electron density suddenly produced in the normal daytime $E$ layer. The electron distribution existing at the time of this release is shown in figure 1. Dashed portions of the nonmonotonic profile represent "valley distributions" which have been estimated from continuity with the other parts of the distribution calculated from the ionograms. The $\mathrm{SF}_{6}$ was released in such a valley, above a natural "ledge"; the electron density at the point of release is estimated as $1.2 \times 10^{5} / \mathrm{cm}^{3}$. Two ionograms, at 1311 (before release) and at 1313 (1 min after release) are shown in figure 2. Tracings of these and other ionograms 

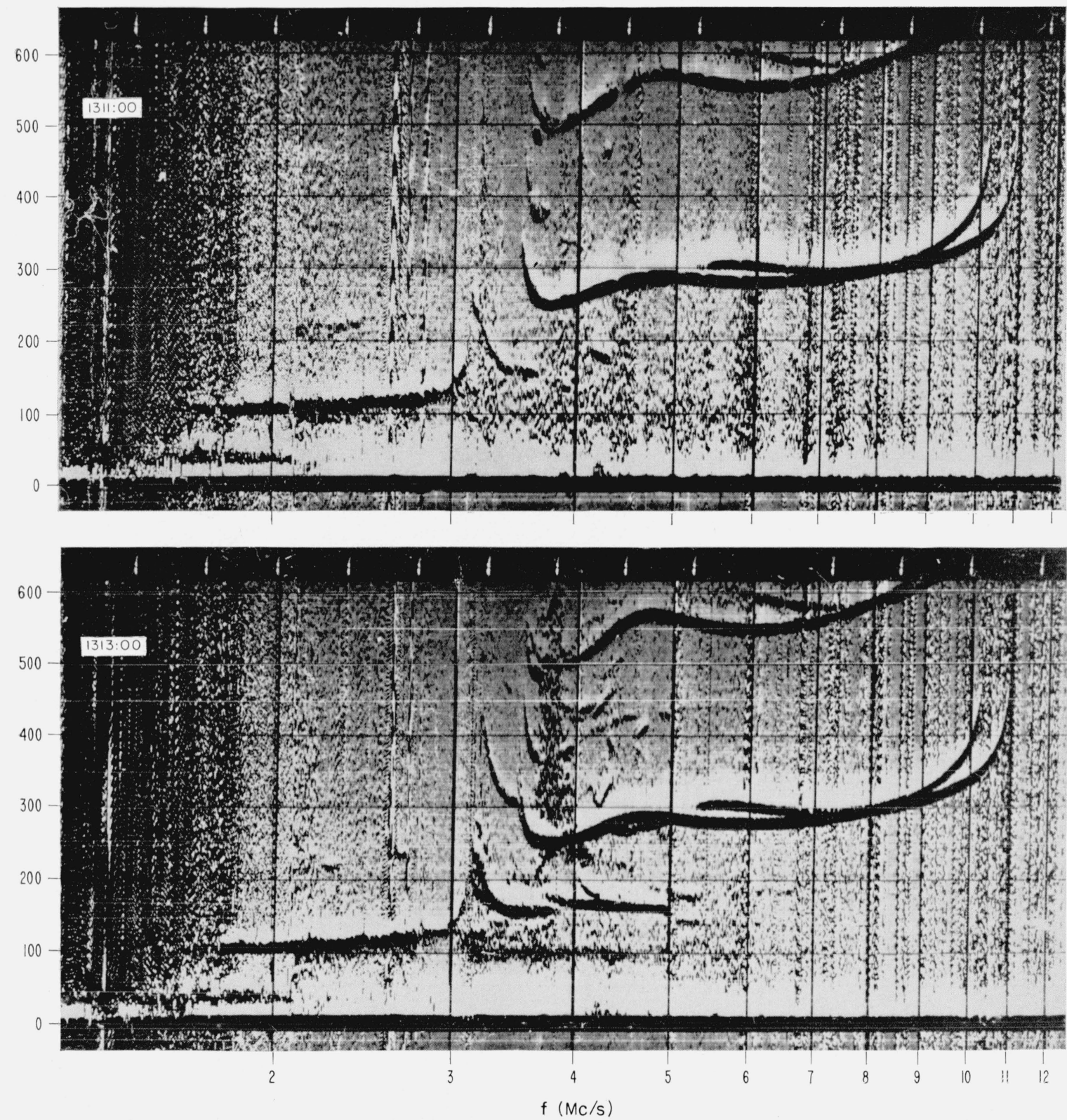

Figure 2. Ionograms during Firefly Ethel before (1311:00) and shortly after (1313:00) release of $\mathrm{SF}_{6} \mathrm{at} 137 \mathrm{~km}$.

each 30 sec from 1310:00 through 1317:30 are shown in figure 3. The release occurred at 1312:01 CST, or at the precise second the ionosonde passed through $4 \mathrm{Mc} / \mathrm{s}$ on the tracing marked 1312:00. No instantaneous effect was noticed, but the following ionograms show a strong echo to $6 \mathrm{Mc} / \mathrm{s}$ at a slant range of $156 \mathrm{~km}$, vestiges of which are visible through 1314:00. At later times, bits of echo are seen at great slant ranges in the vicinity of $f_{0} E-f_{x} E$. If this strong echo is considered to come from a region of increased electron density, this might be accounted for by "snowplow" action (a compression of ambient ionization by the expansion of the material), but other releases of inert material at the same altitude have not shown this effect. A more likely interpretation is that the $\mathrm{SF}_{6}$ has removed electrons from within a bounded region, thereby causing a sharp discontinuity of refractive index across the boundary. The maximum frequency of reflection decays at an approximately constant exponential rate, as seen in figure 4. There is slight evidence for a decrease in the electron density of the ledge at $129 \mathrm{~km}$, following: $1314: 15$, as also seen in figure 4 . 


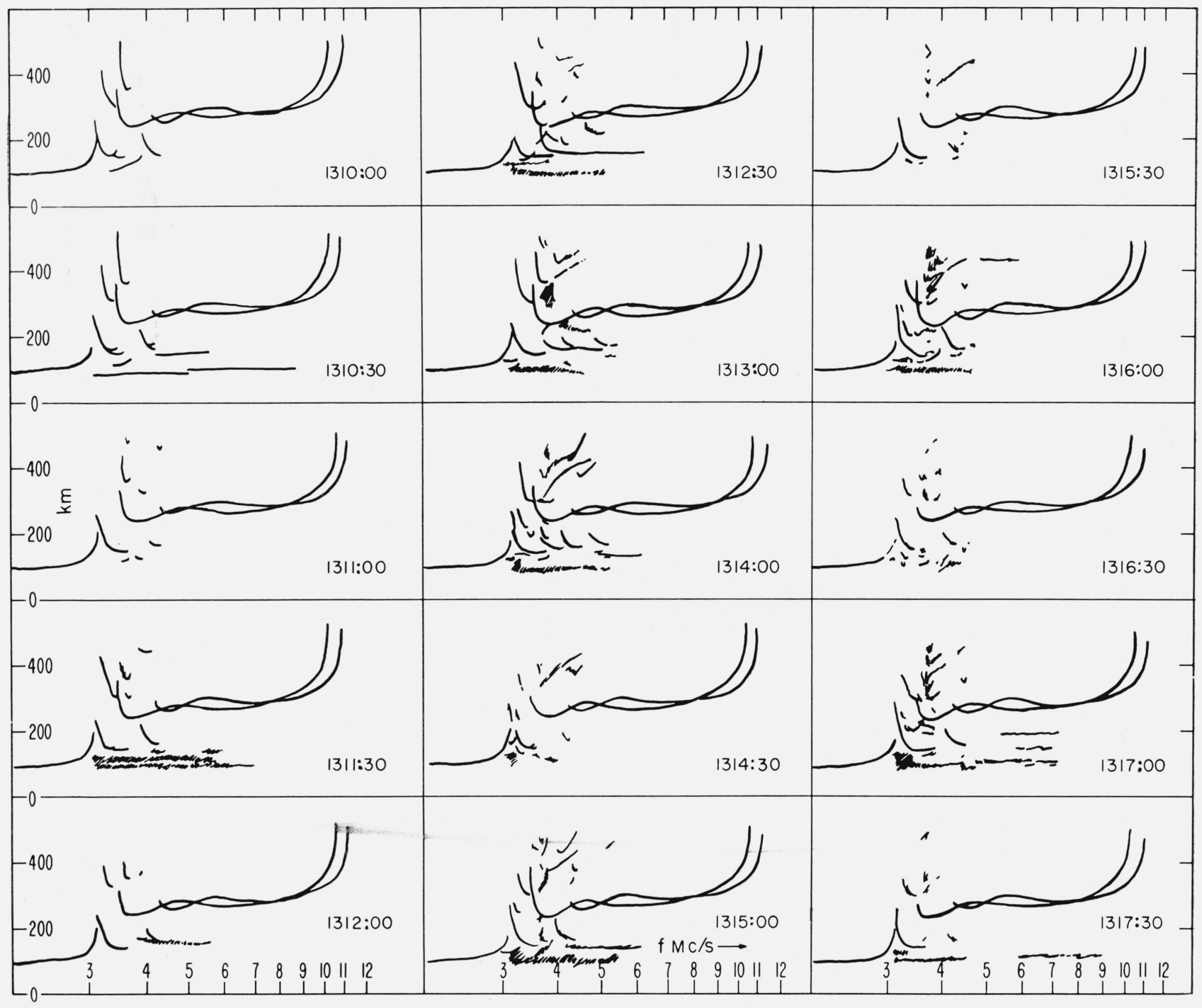

FIGURE 3. Tracings of ionogram sequence, Firefly Ethel, each 30 seconds from 1310:00 through 1317:30.

It should be noted that a similar experiment, with similar results, occurred during the "Firefly 1960" chemical release series [Wright, 1962]. In that experiment (Rena, $14 \mathrm{~kg}$ of $\mathrm{SF}_{6}$ at $105 \mathrm{~km}$, August 19, 1960 , at 1356 CS'T) the most definite effect of the release was again the production of an echo to frequencies exceeding the ambient plasma frequency. These two similar experiments would appear to give conclusive proof that radio reflections resembling "Sporadic E" echoes on ionograms can return from ionospheric regions of sharply reduced electron density.

\subsection{Firefly Fanny}

Four high explosive detonations of $5 \mathrm{~kg}$ each under night conditions; two salted with cesium, as follows:

(1) HEX at $140 \mathrm{~km}$ 1904:48 CST, 10 Nov. 1962

(2) Cs HEX at $157 \mathrm{~km} \mathrm{1905:00}$
(3) $\mathrm{HEX}$ at $230 \mathrm{~km} \quad 1906: 04$

(4) Cs HEX at $260 \mathrm{~km} \mathrm{1908:19}$

These explosive releases were intended to study the effects of shock waves in the $F$-region. The addition of cesium could be expected to enhance the effects of ionization created by the detonation: There has been some uncertainty in the past concerning the relative importance of ionization created in the shock front, versus effects from the ambient ionization, on radio Doppler observations during the first few milliseconds following the burst. It was not expected that for the longer-term effects on the ambient, as seen by ionosondes, an appreciable difference could be detected between the HEX and Cs HEX detonations at these altitudes.

The $N(h)$ profiles (fig. 5) were calculated from ionograms obtained at 1751 and 1906 CST. The 1751 ionogram was good enough to permit a fairly 


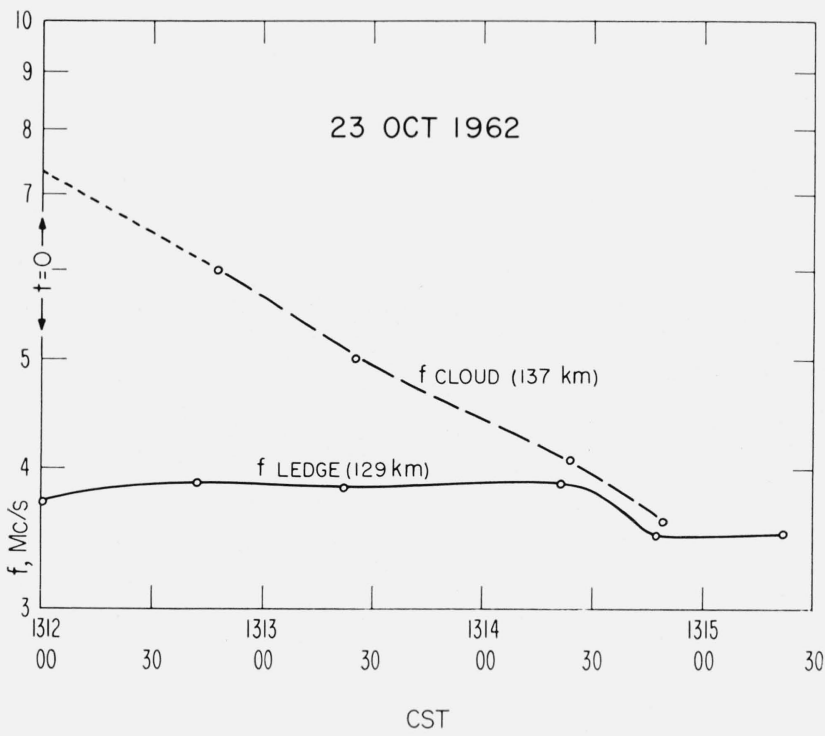

FIGURE 4. Variation with time of the maximum radiofrequency of the echo associated with the Firefly Ethel release of $S_{6}$ at $137 \mathrm{~km}($. . . . ).

The plasma frequency variation of the underlying ledge is also shown (-०—).

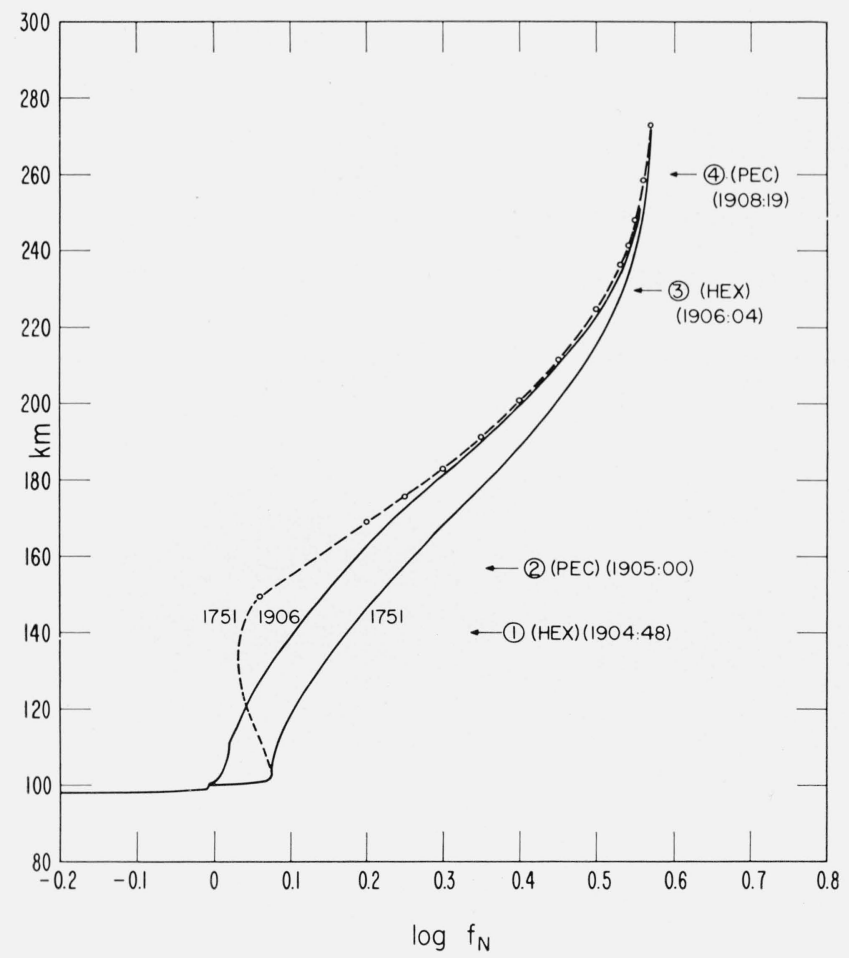

Figure 5. Electron distributions during Firefly Fanny, 1906 CST, 10 November 1962.

The solid curves show "monotonic" profiles at 1751 (before release) and at 1906 CST. The dashed curve represents a profile corrected for a valley above the $E$ region. PEC (point electron cloud, Cs-salted high explosive) and HEX (pure high explosive) release heights are indicated.

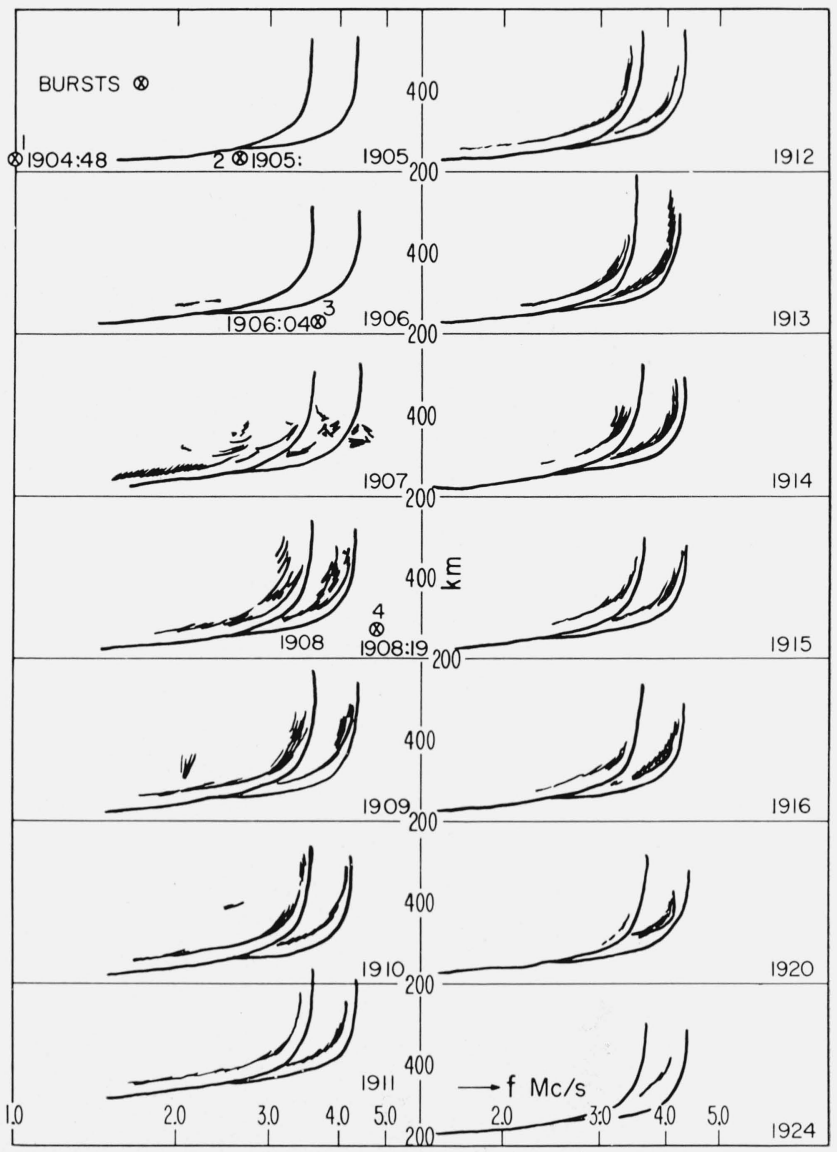

Figure 6. Tracings of ionogram sequence, Firefly Fanny, each minute from 1905 through 1916 CST, plus those at 1920 and 1924 CST.

The times of the four bursts are shown.

accurate (nonmonotonic) $F$-region analysis; this suggests that the 1906 monotonic profile should be everywhere 10 to $20 \mathrm{~km}$ higher than shown, except below $h \max E$.

The first two detonations occurred near the base of the $F$-region, while bursts 3 and 4 occurred near the $F$-peak.

The sequence of ionosonde observations is traced in figure 6. The times of bursts are marked near the various curves in such a way as to show the approximate frequency of the ionosonde at the time of burst.

No effects were seen synchronous with bursts 1 or 2 , but prior to burst 3 (at $230 \mathrm{~km}$; tracing 1906) an echo is seen beyond the $F$-echo between 2 to 2.5 $\mathrm{Mc} / \mathrm{s}$. The real heights of reflection of these frequencies fall between 180 and $220 \mathrm{~km}$. Thus, if burst 2 is responsible for this, it has sent ahead a disturbance which travels from 157 to (say) $200 \mathrm{~km}$ in, at most, $47 \mathrm{sec}$, or at about the upward rocket velocity of one $\mathrm{km} / \mathrm{sec}$. There is somewhat more clear evidence for an effect of the $3 \mathrm{~d}$ burst on the 1907 ionogram. In figure 7, three ionograms from 

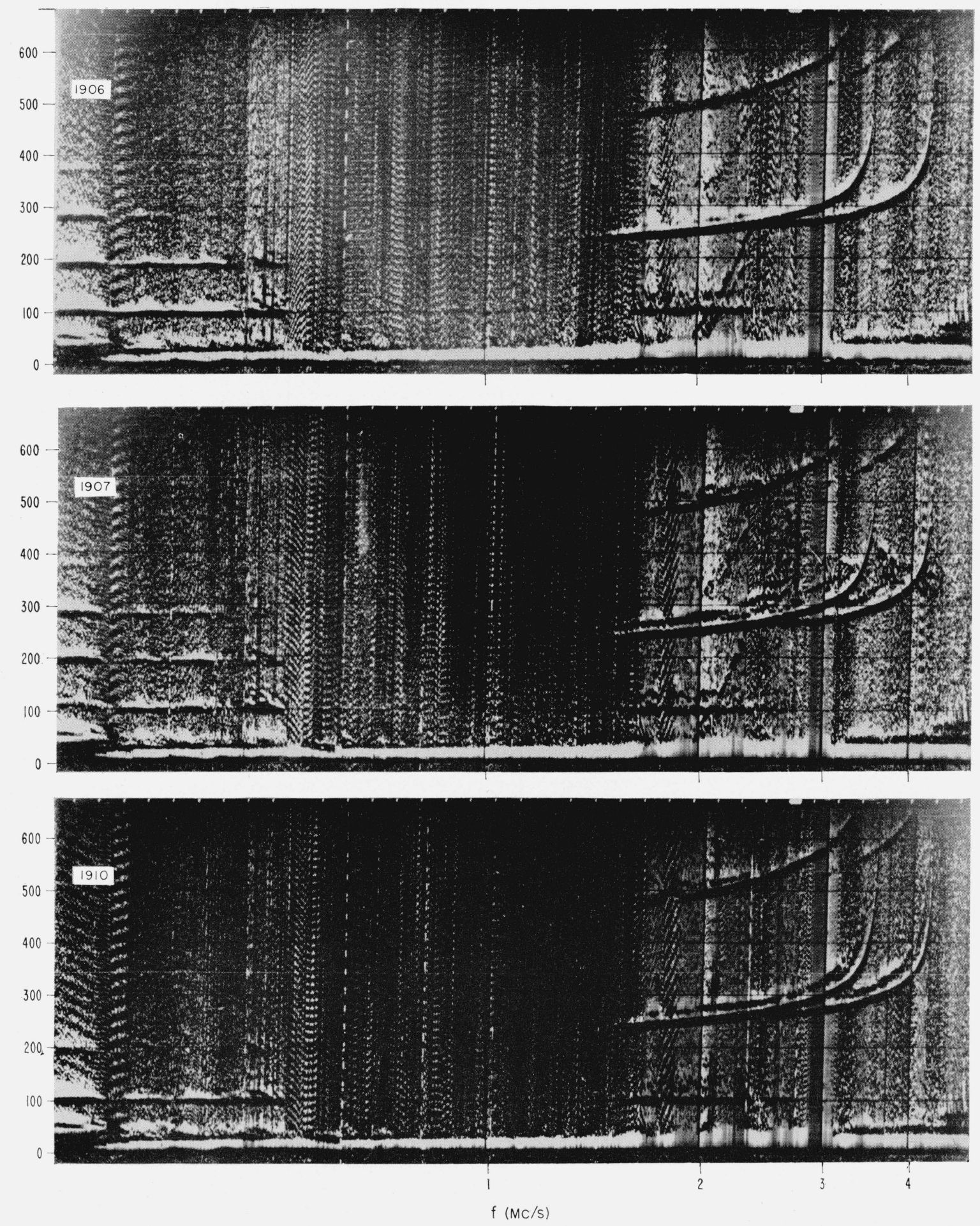

FIgURE 7. Ionograms during Firefly Fanny, just following burst 2 (1906), following burst 3 (1907) and after burst 4 (1910). 


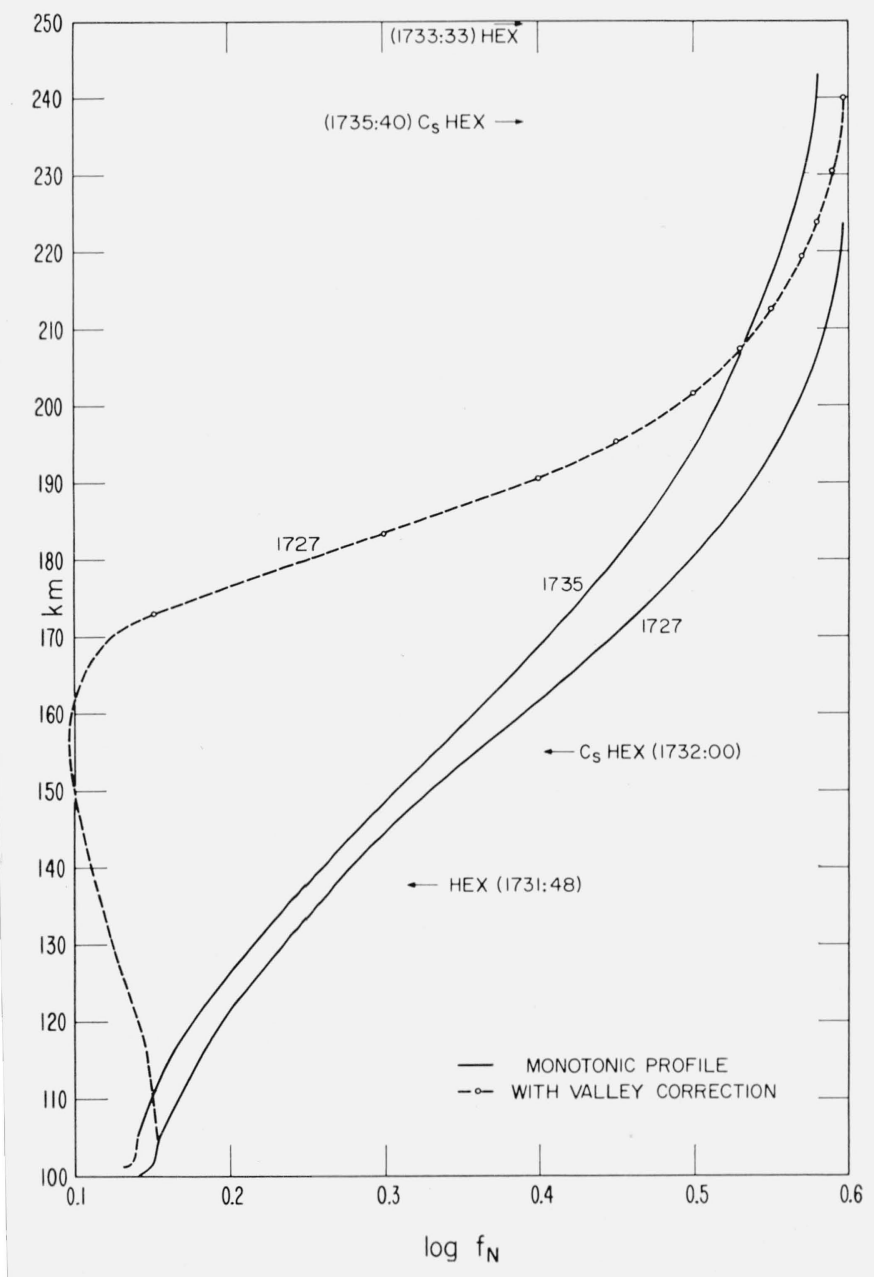

FIGURE 8. Electron distributions during Firefly Gilda, 1727 and 1795 CST, 13 November 1962.

The dashed curve represents a more probable profile. Heights of the various detonations are shown.

the sequence $(1906,1907,1910)$ are reproduced. It is to be noted that none of the new echoes may be seen to a great virtual height. This suggests that the disturbance so far is confined to altitudes below the $F$-peak, and this is to be expected from the positions of bursts 1 to 3 . Following burst 4 (1908) an echo trace is seen which parallels throughout, the ordinary and extraordinary echoes from the ambient $F$-region. The slant range of this echo exceeds the $F$-region virtual height by $25 \mathrm{~km}$, which agrees well with the computed slant range to the burst positions.

While it is not possible to attribute the final disturbances (after 1909) to one or another of the individual detonations, it is fairly clear that the aggregate effect was similar to the natural "traveling" ionospheric disturbances" frequently seen on ionosonde recordings. Such echoes would occur, for example, from a "step" in each electron density contour such that, within a limited region, the electron density was less at each height than outside the region. Most of the energy of these detonations is ultimately dissipated in the form of heat; the heated region expands, and the ion density within it becomes smaller, thereby producing a region of the kind required by these observations.

\subsection{Firefly Gilda}

Four high explosive detonations of $5 \mathrm{~kg}$ each under sunlit conditions; two salted with cesium, as follows: (1) HEX at $137.7 \mathrm{~km}, 1731: 48,13$ November 1962

(2) CsHEX at $155 \mathrm{~km}, 1732: 00$

(3) HEX at $250 \mathrm{~km}, 1733: 33$

(4) CsHEX at $237 \mathrm{~km}, 1735: 40$

This experiment was similar to the one just discussed (Fanny), except that it was conducted under sunlit conditions at the altitudes of detonation. We shall attempt to contrast these two experiments in the following discussion. The ambient electron density distributions are shown in figure 8 . Solid curves show "monotonic" calculations; the dashed curve represents a profile corrected for a valley above the $E$ region. The first two bursts occurred in the valley, while the third and fourth occurred near or above the $F$-peak. No effect whatever may be seen of the first detonation. There is no evidence that the first burst of Fanny produced an $F$-region effect, either, so that the effects of a simple high explosive in regions of low electron density do not seem significant to these observations whether sunlit or not. The second burst, salted with cesium, produced a direct echo to the ionosonde seen at a slant range of $165 \mathrm{~km}$ in the ionogram (1732:00) of figure 10. It is also shown in the sequence of ionogram tracings of figure 9. The computed slant range to the burst position is $155 \mathrm{~km}$. At least $8 \mathrm{~km}$ of this discrepancy may be accounted for by retardation in the underlying ionization. Incidentally, it may be noted that the fact that this direct echo shows little or no decrease of virtual range with increasing frequency, argues for a low ambient plasma frequency at the height of the electron cloud, thus tending to confirm the dashed curve of figure 8 as the correct profile. A slight "branching" of the $F$-echo can be seen simultaneously with the direct cloud echo. It could perhaps be explained as an oblique echo to an existing. $F$-region irregularity via the electron cloud. Alternatively, it may be that the detonation has directly caused an $F$-region disturbance. In either case, these echoes come from that part of the $F$ - region profile between about 210 to $225 \mathrm{~km}$. Careful inspection shows that they disappear when the direct cloud echo disappears (at 1736:30).

No effects are synchronous with the $3 \mathrm{~d}$ or 4 th bursts, but a new type of $F$-region disturbance begins about one minute after burst 3 , and develops strongly after burst 4 . Note (from fig. 8) that these bursts occur near or above the $F$-peak. Reasonably, these new echoes are seen first at high frequencies (see fig. 9 ) and then at later times at lower frequenciesi.e., at lower electron densities and lower heights; the disturbance thus propagates downward through the $F$-region.

As with Firefly Fanny, the echoes from the disturbance are what could be expected from a region 


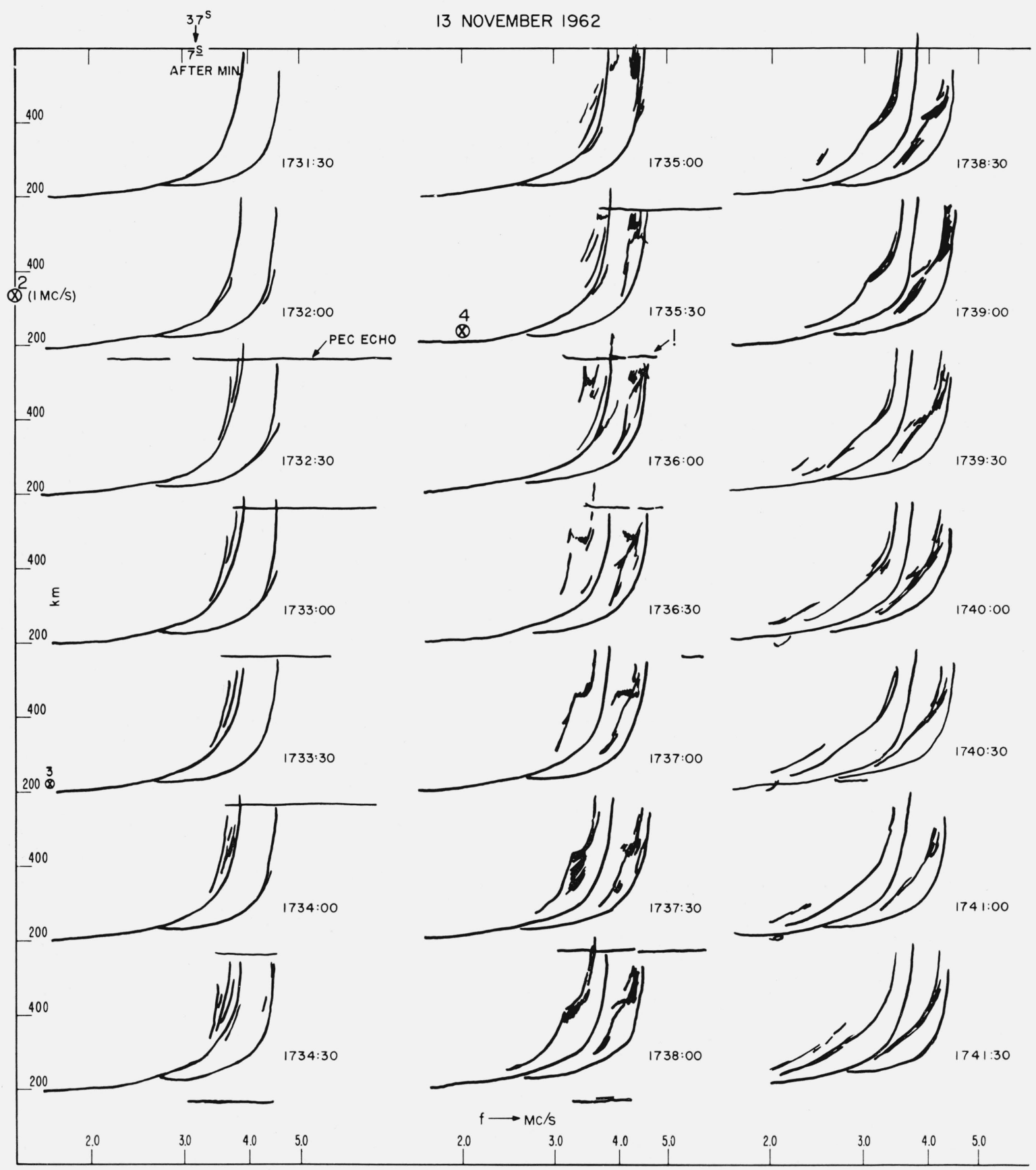

Figure 9. Tracings of ionogram sequence, Firefly Gilda, each 30 seconds, from 1731:30 through 1752:00. PEC echo (1732:00) represents a direct echo to the ionosonde from the point electron cloud (Cs HEX) released at $155 \mathrm{~km}$. 
13 NOVEMBER 1962

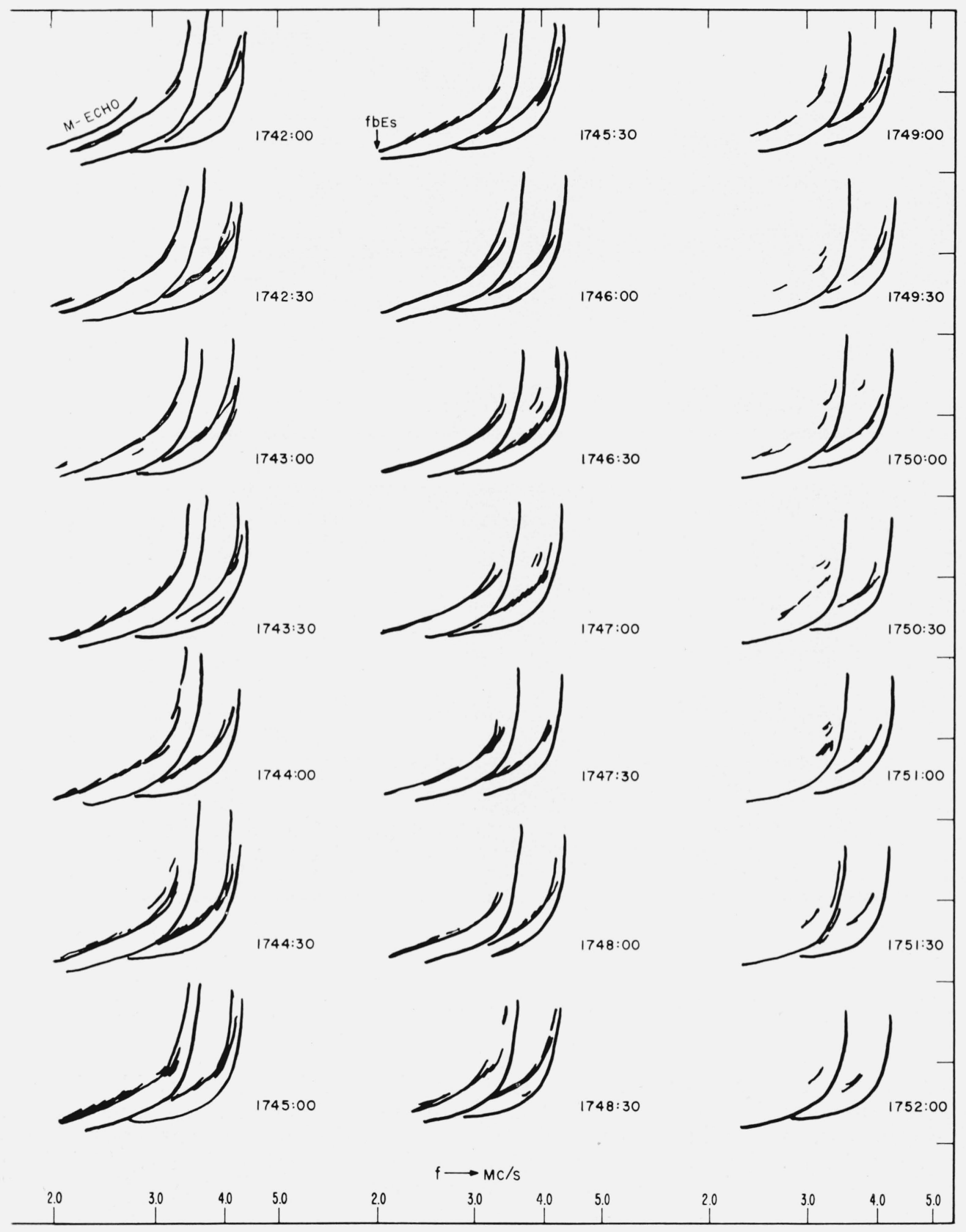

Figure 9. Tracings of ionogram sequence, Firefly Gilda, each 30 seconds from 1731:30 through 1752:00-Continued 

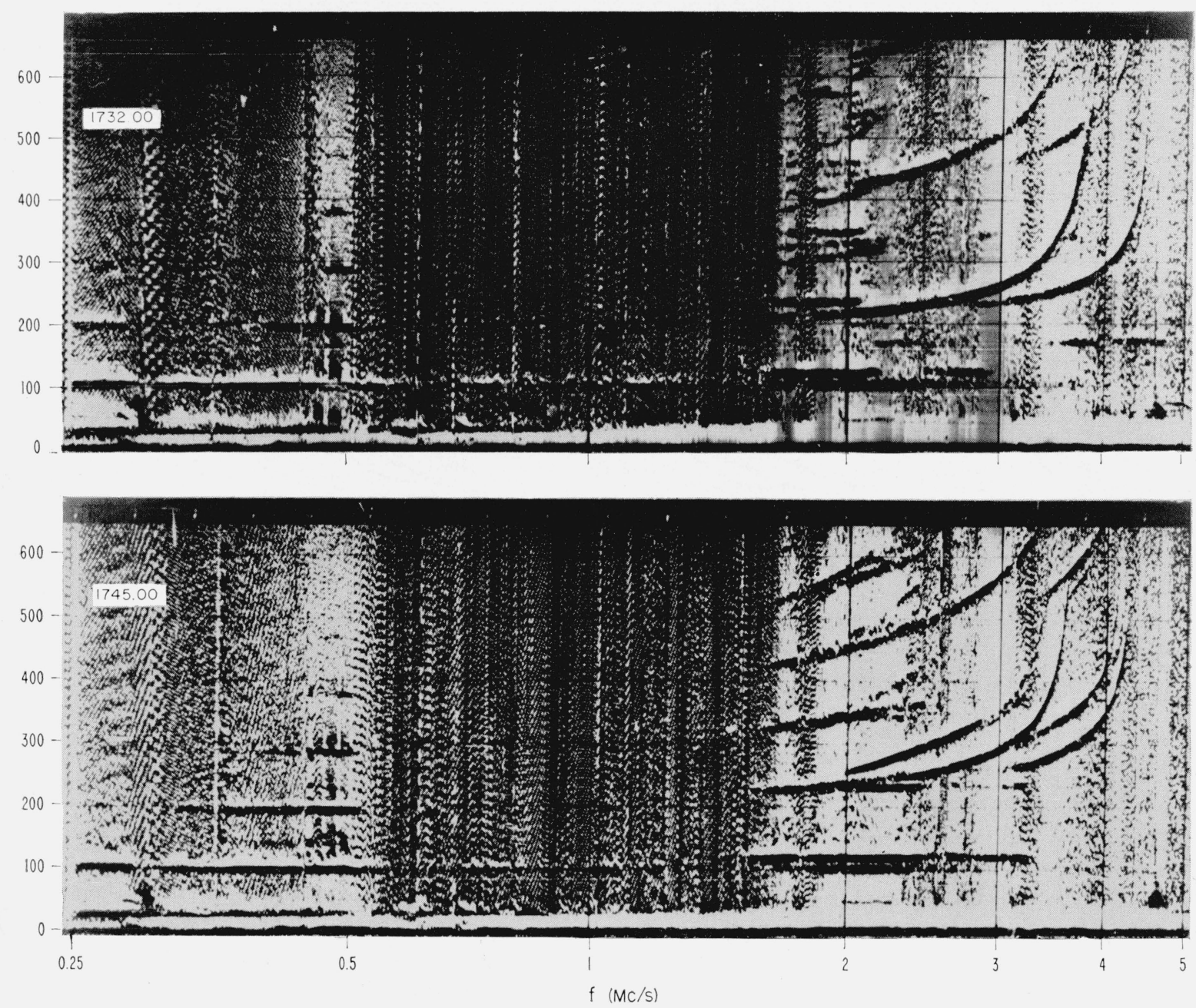

Figure 10. Ionograms during Firefly Gilda just after burst 2 (1732:00) and almost 10 minutes following burst 4 (1745).

of reduced electron density, surrounded by the unaffected region. The total duration of these echoes is about the same in both experiments, $17 \mathrm{~min}$ in the present case, versus 19 min for Fanny. Thus, the presence of sunlight does not seem appreciably to have affected the lifetime of the disturbance. On the other hand, an interesting difference is seen in the cusp which propagates downward from 1735 through 1741, in the present experiment. The presence of this cusp, together with the development of the entire disturbance, suggests that the electron density is decreasing at two different rates above and below the (height) level of the cusp, as the whole structure moves down through the layer. The general disturbance might be explained, as in the case of Fanny, by a decrease of electron density due to thermal expansion of the region; in this case, it is moderated at the greater height by downward diffusion of the ionization being formed at still greater altitudes under sunlight.
In both experiments, it is remarkable that no evidence of movement is seen, i.e., the slant range of the disturbance echoes remains essentially constant through the lifetime of the disturbance. This is in marked contrast with the well-known "traveling" behavior of the natural disturbances to which the echoes associated with these irregularities otherwise bear a strong resemblance.

\subsection{Firefly Karen}

Release of $5.44 \mathrm{~kg} \mathrm{CO}_{2}$ and $18.14 \mathrm{~kg} \mathrm{SF}_{6}$ at 234 and $225 \mathrm{~km}$, respectively, in the nighttime $F$-region, 1929:35 and 1931:35 CS'T, 15 November 1962.

Releases of these substances were intended to accomplish a reduction in $F$-region electron densities without the introduction of thermal energy. $\mathrm{CO}_{2}$ is released in great quantities in the exhaust of large rockets, and might accelerate the dissociative re- 
combination process by which $F$-region electrons normally disappear through the reaction

$\mathrm{CO}_{2}+\mathrm{O}^{+} \rightarrow \mathrm{O}_{2}^{+}+\mathrm{CO}$ together with $\mathrm{O}_{2}^{+}+e \rightarrow \mathrm{O}^{\prime}+\mathrm{O}^{\prime \prime}$.

The high electron affinity of $\mathrm{SF}_{6}$ would be expected to lead to an even more marked reduction in electron density [Golomb, 1962]. The electron density profile (fig. 11) shows that both releases occurred near the peak of the $F$-region. The sequence of ionograms is traced in figure 12. Altogether, it seems certain that large effects were produced, but some ambiguity exists regarding the significance of the $\mathrm{CO}_{2}$ effect because a natural disturbance seems to have occurred shortly before its release. About 35 seconds before the $\mathrm{CO}_{2}$ release, a large meteor was observed visually at a low elevation angle; this may have been seen by the ionosonde by reflection in the $F$-region, and thus might account for the echoes seen at 1928:30 and 1929:00, prior to the $\mathrm{CO}_{2}$ release. There is, in any case, no remarkable enhancement of the disturbance after this release, nor until after the release of the $\mathrm{SF}_{6}(1931: 35)$.

If one ignores the disturbance echoes starting at low virtual heights (through 1932:00), it is possible to identify a sequence of cusp-shaped echoes which proceed downwards (with time) from great virtual heights near foF2. Two typical ionograms from this sequence are shown in figure 13 . The impression of downward moment is quite marked, and may probably be associated with the downward diffusion of the cloud of $\mathrm{SF}_{6}$ through the $F$-region.

It is puzzling to consider the process by which this region of reduced electron density returns to normal. As with the high explosive releases discussed above, there is no evidence of rapid lateral translation of the region. The echoes from the region simply become weaker and disappear over a period of several minutes. A possible interpretation is that the region returns to normal in isolated pockets which gradually grow, leaving a diminishing outline of the disturbed region which finally cannot be detected.

\subsection{Firefly Martha}

Release of $22.68 \mathrm{~kg} \mathrm{SF}_{6}$ at $222 \mathrm{~km}$ in the daytime F-region, 1134:35 CST, 15 December 1962.

One difficulty with the two electron removal experiments described above, is that the effects exist well beyond the observable lower limit of the nighttime $F$-region; it is clear from the observations that large perturbations occur near and below the base of the $F$-region where observations become more difficult because of strong broadcast-band interference to the radiofrequencies reflected there. A daytime experiment was therefore conducted, in which, despite a single large release of $\mathrm{SF}_{6}$, the effects were anticipated to be confined at lower heights by rapid electron production, and photodetachment of $\mathrm{SF}_{6}$, at approximately $F 1$ layer levels (180 to $200 \mathrm{~km}$ ).

The electron density distribution at the time of the release is shown in figure 14. No "valley correction" was possible here, because of the configura-

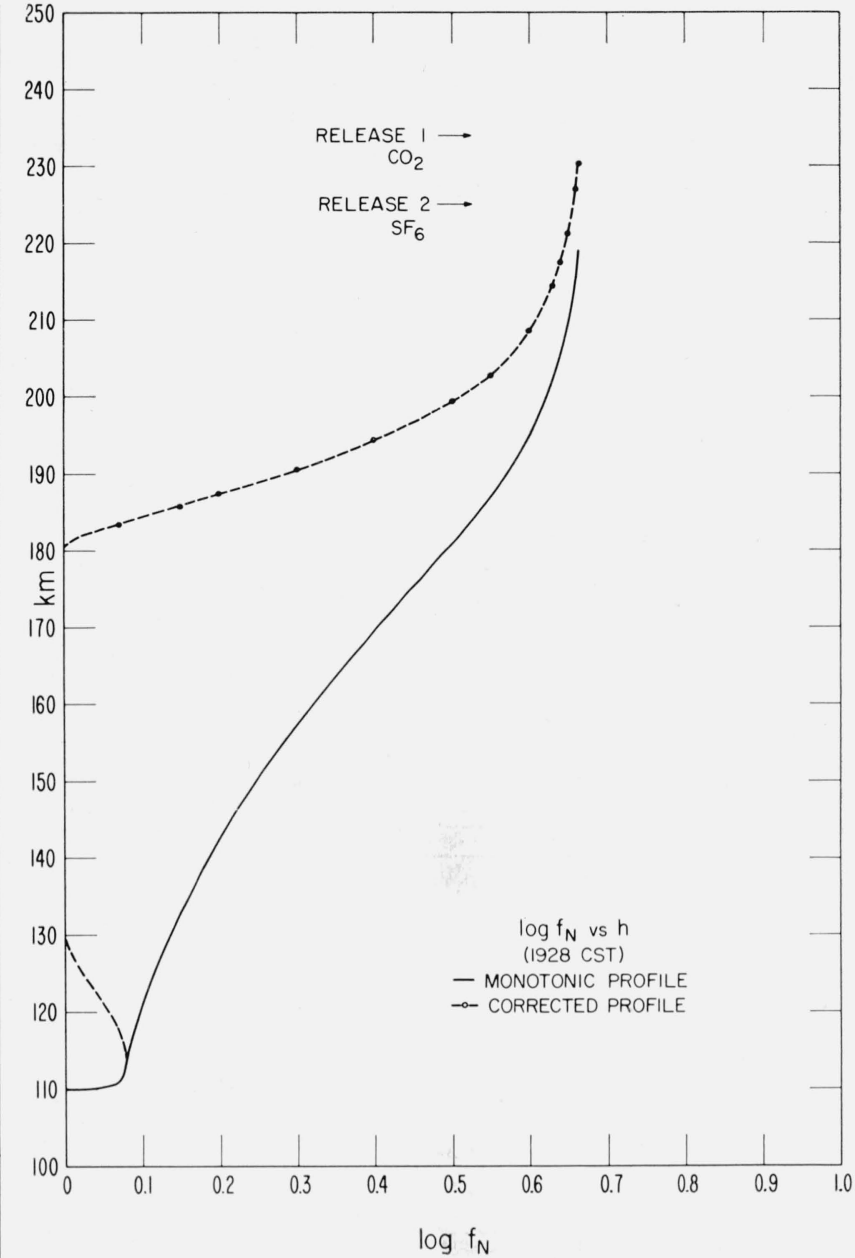

Figure 11. Electron distribution during Firefly Karen, 1928 CST 15 November 1962.

Dashed curve represents a more probable profile, taking account of a valley above the $E$ layer.

tion of the distribution near $f_{0} E$; thus, the lower part of the correct $F$-region profile may be somewhat higher than shown, although little error is to be expected near the $F 2$ peak. The $\mathrm{SF}_{6}$ was released just below the $F 2$ peak, at $222 \mathrm{~km}$. An effect was seen no more than $7 \mathrm{sec}$ after the release -i.e., by the time the ionosonde reached frequencies capable of penetrating the $F 2$ peak. The first echoes are, in fact, only at frequencies greater than fo $F 2$, and suggest that for a short time, the cloud was able to support propagation via a triangular path near the F-peak. "The "MUF" for such a path would exceed foF2. This echo, in its early stages, is similar to the virtual slant-range versus frequency curve typical of oblique-incidence pulse sounding's.

Ionograms from the sequence are shown in figure 15. It is clear that many complicated ray paths have occurred between the cloud, surrounding $F$-region, and the ionosonde; of course, each path appears twice, because of magneto-ionic splitting. 
I5 NOVEMBER 1962

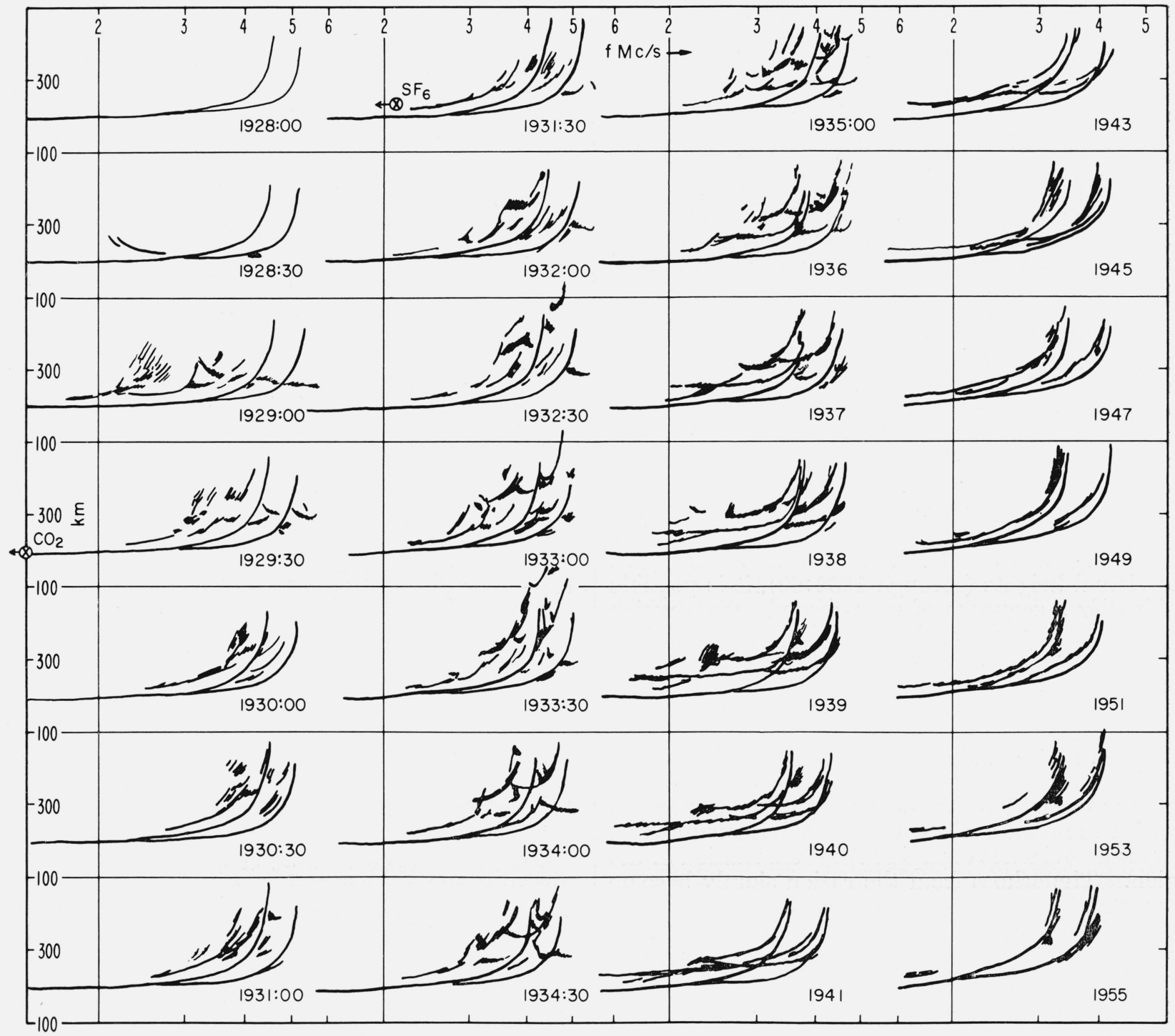

FIguRE 12. Tracings of ionogram sequence, Firefly Karen, at various intervals as shown between 1928-1955 CST.

The lowest frequency echo, on each ionogram of the sequence, is part of an echo trace which may be followed with complete continuity of height, frequency, and time. It is quite clearly of the kind described by Booker [1961] as the typical echo pattern from a region of reduced electron density embedded in a surrounding medium. As this echo develops to lower frequencies, this implies the downward progress of the $\mathrm{SF}_{6}$. The very lowest frequency echo marks the lowest electron density contour sufficiently affected by the $\mathrm{SF}_{6}$ to render a reflection to the ionosonde; the height (judged from fig. 14) at which this occurs, versus time, is shown on figure 16. It may be seen that after about 2 min, the lower edge of the cloud appears to descend at an exponentially decreasing velocity with decreasing height.

Another part of the "principal echo" measures approximately the minimum plasma frequency in the depleted region. It starts with a value near foF2 (at 1135:00) and gradually decreases to a minimum value approximately equal to "fo $F 1$ " by $1200: 00$. This development proceeds in such a fashion that the "lowest contour affected" and the "minimum plasma frequency in the depleted region" become equal as they approach foF1. It is possible that the minimum plasma frequency in the region becomes actually less than $f_{0} F 1$, but as $f_{0} F 1$ does not decrease this would not be visible.

Thus, the sequence of events seems to be this: The $\mathrm{SF}_{6}$, upon release, expands within at most a few seconds to a sphere of about $3 \mathrm{~km}$ diameter at ambient pressure [Golomb, 1962], containing about 100 moles of gas, or about $10^{26}$ molecules. The cloud of $\mathrm{SF}_{6}$ continues to expand laterally by diffusion, and falls vertically by diffusion and gravity. 

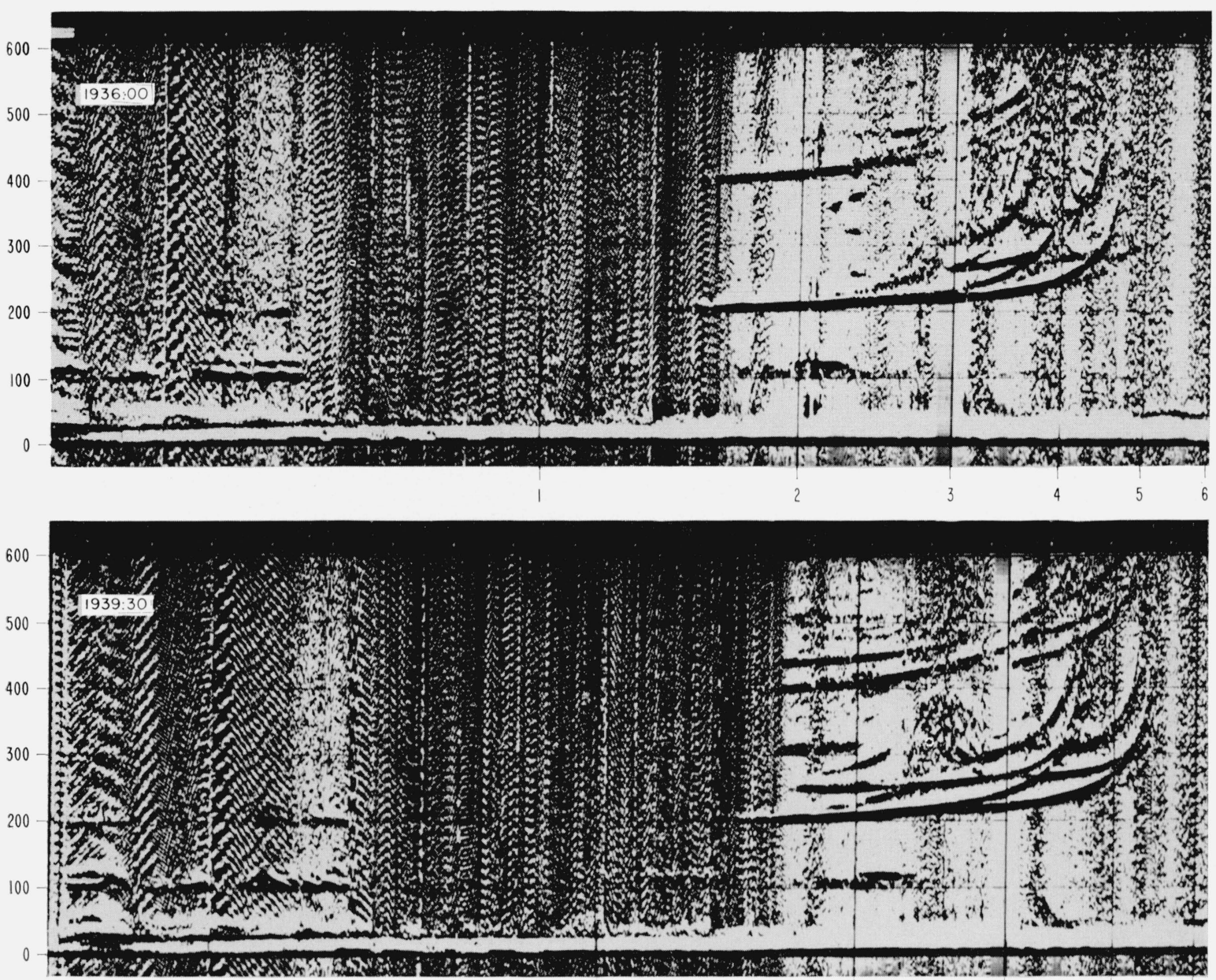

$f(M C / S)$

Figure 13. Ionograms during Firefly Karen at two times following release of $S_{6}{ }_{6}$ near the F2 peak.

As long as the concentration of $\mathrm{SF}_{6}$ considerably exceeds the ambient electron concentration, the latter will be appreciably reduced in the cloud because of the rapidity of the attachment process. Electrons from above the cloud diffuse rapidly into it, although only along the nearly vertical geomagnetic field, and at a vertical rate reduced by the factor $\mathrm{Sin}^{2}$ (magnetic dip), or at about 75 percent of the vertical rate ignoring the geomagnetic field. Thus, the hole becomes elongated along the magnetic field by electron-ion diffusion from above the cloud, and develops to lower altitudes by vertical diffusion under gravity of the $\mathrm{SF}_{6}$.

The vertical descent of heavy molecules in the atmosphere has been discussed by Banister and Davis [1962], Granzow [1962] and by Shearman [1962]. By several approaches to this problem, these authors show that upon release an arbitrary distribution of molecules will tend to a constant vertical profile de- scribed by the familiar "Chapman" form ${ }^{1}$ in a time of the order

$$
\tau_{0}=\frac{\rho_{0} H_{0}}{K},
$$

where $\rho_{0}$ is the atmospheric density and $H_{0}$ the scale height at the point of release, and $K$ a constant characteristic of the molecules and the atmosphere. $K$ is given by

$$
K=\frac{3 / 8 g[m M(m+M)]^{1 / 2}}{(a+A)^{2}(2 \pi k T)^{1 / 2}}
$$

where

$a, A$ are the radii of air and $\mathrm{SF}_{6}$ molecules;

$m, M$ are the air and $\mathrm{SF}_{6}$ masses;

$k$ is Boltzman's const.; $g$ is the gravitational const.; $T$ is the absolute temperature.

\footnotetext{
1 The authors cited do not note tha correspondence to the Chapman form.
} 
To evaluate $\tau_{0}$ in the present case, we choose atmospheric parameters from the tables of Harris and Priester [1962] appropriate to the level of solar activity $(10.7 \mathrm{~cm}$ solar flux index 76$)$. The value of scale height is obtained from the $N(h)$ profile by methods described by Wright [1962]; the value so determined $(27 \mathrm{~km})$ is consistent with the Harris and Priester tables for these conditions. The radius and mass of $\mathrm{SF}_{6}$ are given by Golomb [1963]. The parameters used in the calculations are evaluated at the level of release $(222 \mathrm{~km})$ and are as follows:

$$
\begin{aligned}
m & =4.81 \times 10^{-23} \mathrm{~g}, \\
a & =1.70 \times 10^{-8} \mathrm{~cm}, \\
M & =2.44 \times 10^{-22} \mathrm{~g}, \\
A & =3.5 \times 10^{-8} \mathrm{~cm}, \\
T & =600{ }^{\circ} \mathrm{K} \text { at } 222 \mathrm{~km}, \\
H_{0} & =27 \mathrm{~km} \text { at } 222 \mathrm{~km}, \\
\rho_{0} & =6 \times 10^{-14} \mathrm{~g} \mathrm{~cm}^{-3} \text { at } 222 \mathrm{~km}
\end{aligned}
$$

from which

we find

$$
K=3.5 \times 10^{-10} \mathrm{~g} \mathrm{~cm}^{-2} \mathrm{sec}^{-1} ;
$$

$$
\tau_{0}=464 \mathrm{sec} \text {, or } 7.75 \mathrm{~min} \text {. }
$$

For time $t>>\tau_{0}$, the theory shows that the cloud should retain its constant profile form, the whole cloud then falling under diffusion and gravity with the velocity

$$
V=-\frac{K}{\rho}
$$

This value of $\tau_{0}(7.75 \mathrm{~min})$ is clearly much longer than the time required by the cloud to assume an exponentially decreasing rate of descent as seen in figure 16. A more reasonable value is about $2 \mathrm{~min}$, as marked on the figure. This discrepancy might result from the assumption of too large a value for the atmospheric density, $\rho_{0}$, at the point of release, but this seems unlikely considering the agreement between observation and the model atmosphere regarding scale height. An alternative possibility is that the $\mathrm{SF}_{6}$ falls as a "snow" of conglomerate particles of larger mass than that of a single molecule; this might result from its lowered temperature during the rapid initial expansion of the $\mathrm{SF}_{6}$ cloud.

In the subsequent discussion the value of $\tau_{0}$ calculated above is therefore ignored, and the data are compared with the theory employing the value of $\tau_{0}$ shown in figure 16 .

In an atmosphere of slowly variable scale height $H$, this leads to the following equation for the motion of the cloud between times $t_{1}$ and $t_{2}$ (measured from the instant of release), where $H$ is taken as a mean value between nearby levels $h_{1}$ and $h_{2}$ :

$$
h_{1}-h_{2}=H \ln \left(\frac{t_{2}+\tau_{0}}{t_{1}+\tau_{0}}\right) \text {. }
$$

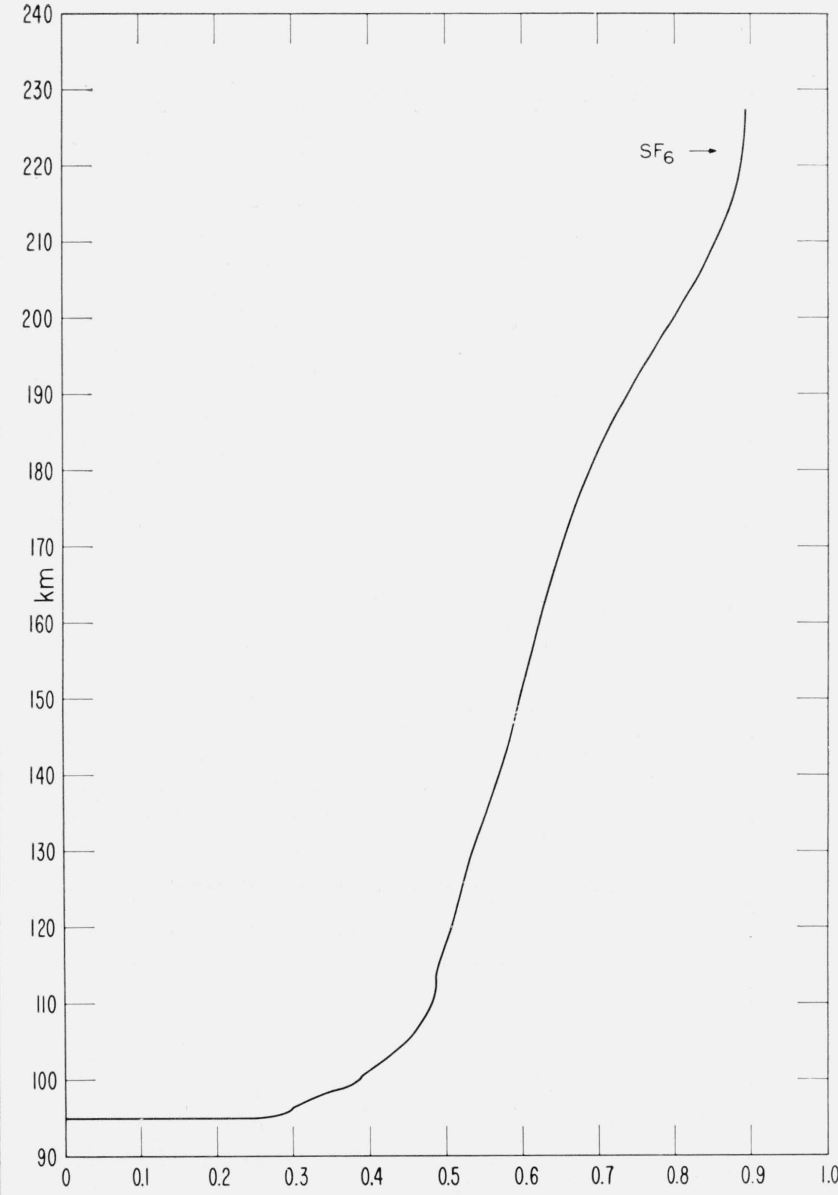

Figure 14. Electron distribution during Firefly Martha, 1134 CST 15 December 1962.

$\mathrm{SF}_{6}$ was released at $222 \mathrm{~km}$, somew hat below the $F 2$ peak.

Using the value of $\tau_{0}$ inferred from the observed cloud-height variation, the cloud height versus time in the model atmosphere may be calculated. The results are shown as the dashed line in figure 16 .

The observed cloud height variation is substantially in agreement with that calculated from (4), although some $5 \mathrm{~km}$ lower everywhere. The correspondence of the calculations with the observed rate of fall is quite good, which suggests that the model atmosphere is appropriate to these conditions, and that the discrepancy in $\tau_{0}$ noted above may indeed result from the conglomeration of $\mathrm{SF}_{6}$ molecules into heavier particles, at least during the period up to approximately $\tau_{0}$.

The calculated values seem to refer to a height averaging $5 \mathrm{~km}$ above the observations. This may result from a variety of factors. The height of release of the $\mathrm{SF}_{6}$ may have been somewhat less than that assumed, or the $N(h)$ profile may be slightly low because of the monotonic assumption used in the analysis. But the most likely explanation for this height shift is found in the cloud process itself, and relates simply to the growth of the cloud into the 

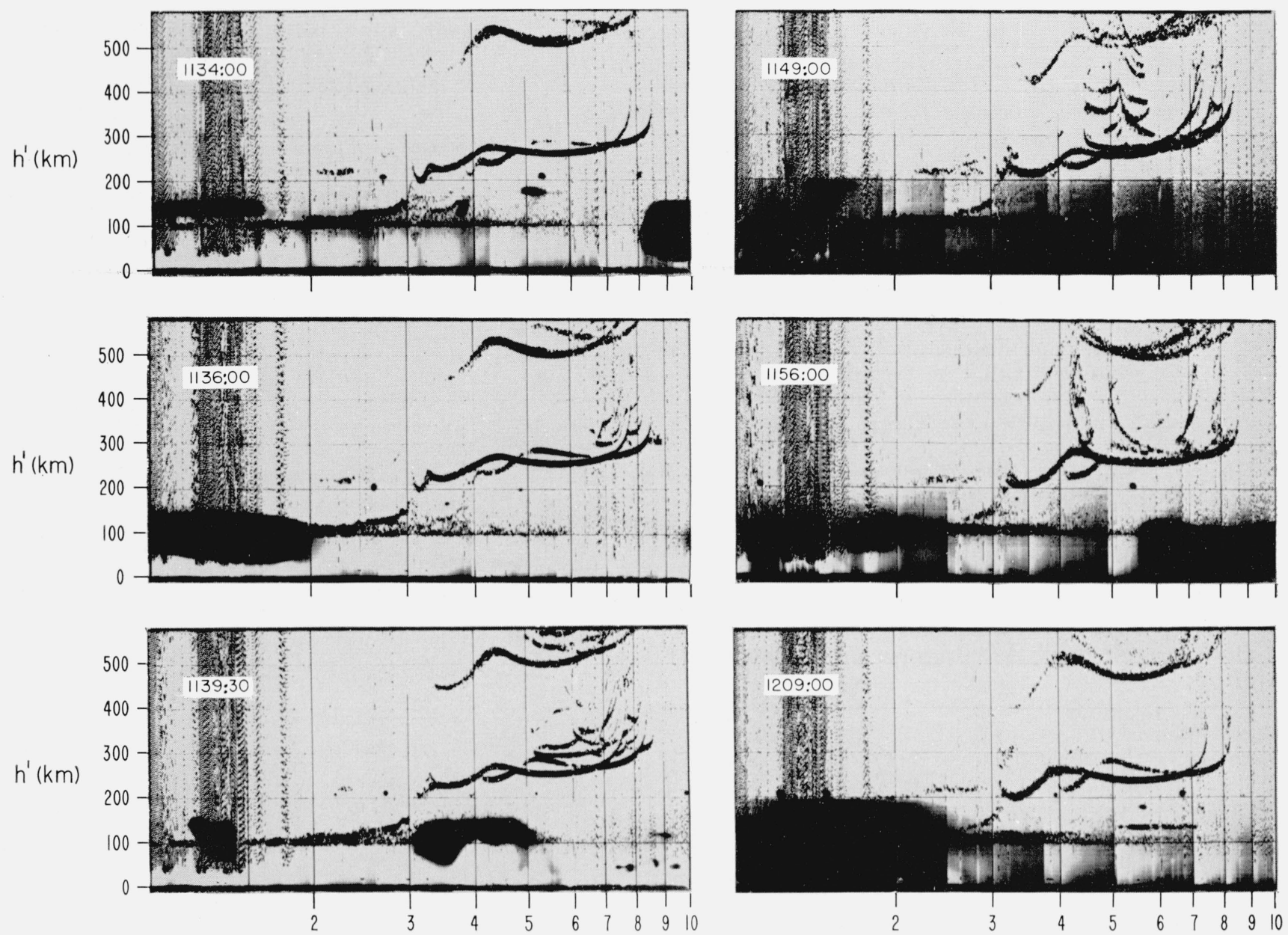

$f(\mathrm{MC} / \mathrm{s})$

Figure 15. Ionograms during Firefly Martha at six typical stages in the development of the disturbance.

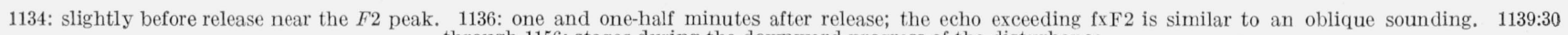
through 1156: stages during the downward progress of the disturbance.

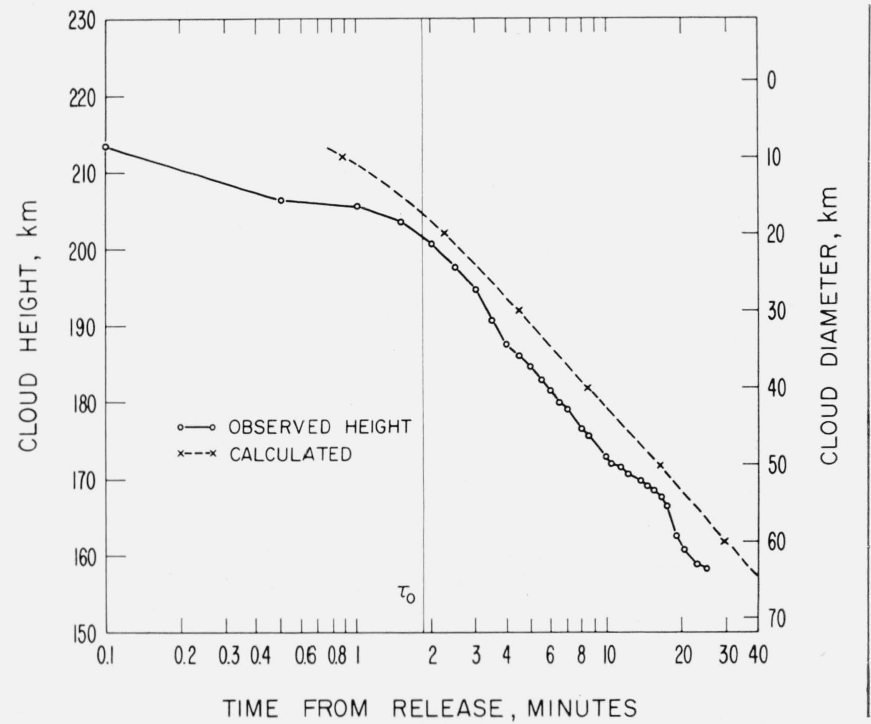

Figure 16. Height of the lowest electron density affected by $S F_{6}$, versus time, Firefly Martha, together with calculated values. Right hand scale: inferred cloud diareter. 
constant profile form, before time $\tau_{0}$. The calculations above strictly pertain to the point of maximum $\mathrm{SF}_{6}$ density, i.e., the peak of the constant profile cloud, and initiate at the release altitude of $222 \mathrm{~km}$. The selected echo from the ionosonde observations, on the other hand, pertains to points on the lower edge of the cloud, along which just enough $\mathrm{SF}_{6}$ exists to warp the electron density contours sufficiently to render a reflection to the ionosonde. It is not unreasonable that these points lie some $5 \mathrm{~km}$ below the cloud peak.

An interesting rule is obtained by Shearman (loc. cit), who shows that the lateral spread of the cloud is always equal to the total distance of descent. We therefore infer that after $30 \mathrm{~min}$, the cloud has assumed a diameter equal to its descent of $80 \mathrm{~km}$. The inferred lateral growth of the cloud, versus time, is also illustrated in figure 16 , by the scale at the right.

It is reasonable that no effects are apparent much below the level of the $F 1$ layer $(145 \mathrm{~km}$.). In this region the rate of electron production becomes small. These processes limit the effectiveness of $\mathrm{SF}_{6}$ at this level or below.

The efficiency and careful planning of the program of twenty-seven rocket launchings by the Air Force Cambridge Research Laboratory, under the leadership of Dr. N. W. Rosenberg, was essential to the success of the observations by the participating agencies. Many of the NBS staff contributed directly to the observations reported here, especially by G. H. Stonehocker, E. J. Violette, and J. J. Pitts.

The author expresses his appreciation to T. N. Gautier for many helpful discussions.

\section{References}

Booker, H. G. (1961), A local reduction of $F$-region ionization due to missile transit, J. Geophys. Res. 66, 1073.

Golomb, D. (1963). Artificial electron removal from the $F$-layer, J. Geophys. Res. (in press).

Harris, I., and W. Priester (24 April 1962), Theoretical models for the solar-cycle variations of the upper atmosphere, NASA Institute for Space Studies.

Paul, A. K. (1960), Bestimmung der wahren aus der scheinbaren reflexions höhe, Arch. Elek. Ubertrag. 14, 468; Kritische bemerkungen zur berechnung der "wahren hohen", Geophys. Pura e Appl. 4\%, 69.

Paul, A. K., and J. W. Wright (1963), Some results of a new method for obtaining ionospheric $N(h)$ profiles with a bearing on the structure of the lower $F$-region, J. Geophys. Res. 68, 5413.

Shearman, C. (1962), Qualitative considerations of diffusion in the earth's gravitational field, Physies of Fluids 5, 863.

Violette, E. J., An improved antenna system for ionospheric vertical soundings (private communication).

Wright, J. W. (1960), A model of the ionosphere above $h \max F 2$, J. Geophys. Res. 65, 185.

Wright, J. W. (April 1962), Ionosonde observations of artificially produced electron clouds, Firefly 1960, NBS Tech. Note 135.

Wright, J. W. (1962), Diurnal and seasonal changes in structure of the mid-latitude quiet ionosphere, J. Res. NBS 66D (Radio Prop.), No. 3, 297. 